\title{
KEMAJUAN PENELITIAN BIOSINTESIS MONOTERPENA DAN PERANAN Terpene Cyclase: Suatu Kajian Pustaka
}

\section{PROGRESS OF RESEARCH BIOSYNTHESIS MONOTERPENE AND THE ROLE Terpene Cyclase: A Review}

\author{
Mario Nikolaus Dalengkade ${ }^{1}$, Ferry Fredy Karwur ${ }^{2 *}$ \\ 1) Magister Biologi Universitas Kristen Satya Wacana \\ 2) Fakultas Kedokteran dan Ilmu Kesehatan Universitas Kristen Satya Wacana \\ Email: ferry.karwur@staff.uksw.edu
}

Diterima 27 April Disetujui 27 Desember 2018

\section{INTISARI}

Perpanjangan rantai, pemutusan ikatan- $\pi$, dan penataan kembali ikatan $\mathrm{C}$ dari suatu reaksi kompleks oleh siklase menciptakan substrat universal untuk biosintesis $\mathrm{C}_{10}$. Dari substrat tersebut mengakibatkan melimpahnya $\mathrm{C}_{10}$ di alam. Sehingga disepakati oleh peneliti sebagai postulat. Kajian-kajian mekanika dan genetik juga membuktikan postulat tersebut. Selain itu keterlibatan ion-ion logam sebagai pengikat berperang penting dalam biosintesis $\mathrm{C}_{10}$ dan pengaturannya.

Kata kunci: $\mathrm{C}_{10}-$ Synthase, gen, divalent/monovalent

\begin{abstract}
Chain extension, bond $-\pi$ termination, and rearrangement of $\mathrm{C}$ bonds from complex reactions by cyclase create a universal substrate for $\mathrm{C}_{10}$ biosynthesis. From this substrate it consumes abundant $\mathrm{C}_{10}$ in nature. Approved by the researcher as a postulate. Mechanical and genetic studies also prove the postulate. In addition, metal ions as a binder play an important role in $\mathrm{C}_{10}$ biosynthesis and its regulation.
\end{abstract}

Keywords: $\mathrm{C}_{10}-$ synthase, gen, divalent/monovalent

\section{PENDAHULUAN}

Ditemukannya ke-12 jenis tumbuhan antara lain Myristica fragrans dan Cananga ordorata sebagai penghasil minyak atsiri, sehingga Indonesia dapat memproduksi minyak atsiri yang bernilai ekonomi di dunia (Departemen Perdagangan Republik Indonesia, 2011; Oyen dan Dung, 1999). Dalam tulisan Hofberger et al, (2015) minyak atsiri adalah golongan senyawa terpena dengan monomer berupa unit isoprena $\left(\mathrm{C}_{5}\right)$ berjumalah 200.000, dan dipisahkan menjadi $\mathrm{C}_{10}$ sampai $\mathrm{C}_{40}$.

Jones et al, (2008) melaporkan kandungan dalam Santalum album L. antara lain a-pinene, sabinene, dan limononene merupakan golongan senyawa terpena yakni $\mathrm{C}_{10}$ sebagai pembangun minyak atsiri. Karena $\mathrm{C}_{10}$ bervarietas, sehingga Devon dan Scott, (1972) memetakan berdasarkan hasil rekayasa genetik menjadi 380 spesies dari 15 famili adalah sebagai berikut; rantai lurus $\mathrm{C}_{5}$ (reguler dan ireguler), $\mathrm{C}_{10}$ sikloheksana, $\mathrm{C}_{10}$ untuk 3-siklik, $\mathrm{C}_{10}$ alkaloid, $\mathrm{C}_{10}$ siklopentana, mentana, $\mathrm{C}_{10}$ siklopentana. Menilik kembali mengenai minyak atsiri, teka-teki yang menantang yakni, "bagaimana beragam tumbuhan penghasil minyak esensial menghasilkan begitu beragamnya senyawa monoterpena?” Dalam tulisan ini, akan mengkaji kembali $\mathrm{C}_{10}$ pada lingkupan perubahan rantai $\mathrm{C}$ disebabkan oleh karakteristik siklase.

\section{ALUR KONVENSIONAL BIOSINTESIS MONOTERPANA}

Biosintesis $\mathrm{C}_{10}$ yang telah diuraikan oleh Mahmoud dan Croteau (2002); Dudareva et al, (2004) yakni: 1) penyusunan kedua $\mathrm{C}_{5} / 3$-methylbut-3-enyl phosphono hydrogen phosphate (IPP dengan DMAP), 2) Penyatuan IPP dengan DMAP, guna membentuk geranil pirofosfat (GPP; $\mathrm{C}_{10}$ ); 3) Oleh enzim GPP dirubah ke bentuk utama sub-anggota $\mathrm{C}_{10}$; 4) Pengalihan bentuk utama ke subkeluarga $\mathrm{C}_{10}$ oleh enzim ke berbagai senyawa turunan.

\section{BIOSINTESIS IPP DAN DMAP}

Mahmoud dan Croteau (2002); Banerjee dan Sharkey (2014) mengemukakan IPP maupun DMAP sebagai isomernya ialah hasil lintasan 3,5-Dihydroxy-3methylvalerate (MVA), dan Methyl-D-erythritol phosphate disodium salt (MEP). Sharkey et al, (2008); 
Rohmer et al, (1996); Rodrîguez-Concepción dan Boronat (2002) menyimpulakan bahwa, dalam MEP terdapat 7 strata reaksi enzimatik. Berpangkal di 1-deoxy-d-xylulose5-phosphate sodium salt (IspC) mengkatalisis 2oxidanylidenepropanoate dan triose phosphate (GAP) membentuk deoxyxylulose-5-phosphate (DXP). Selepas itu mengalami redoks akibat IspCase memunculkan MEP lalu dibentuk 4-(cytidine 5'-diphospho)-ME (C2P-ME) oleh MEP-transferase (YgbP), sesudah itu memanfaatkan adenosina trifosfat dengan bantuan 2-phosphotransferase (IspE) menampakan 2-phospho-4-(cytidine 5'-diphospho)2-C-methyl-D-erythritol (IspF). Di dua rekasi akhir transfigurasi terlaksana, karena dibantu protein constitutif subtilisin 3 (GcpE) dan protein kloroplas biogenesis 6 (LytB) untuk mencetak IPP dan DMAP.

\section{REKAYASA Geranil Difosfat (GPP)}

Laporan Jo Davisson et al, (1985); Cane (1979); Poulter et al, (1981); Poulter dan Rilling (1978) yakni reaksi fusi antar atom 1'-4 berlangsung dalam sistem alil (1), kemudian oleh prenyltransferase diubah menjadi GPP asiklik (2) yang merupakan substrat awal pembentukan beragam $\mathrm{C}_{10}$. Peneliti lain adalah Poulter dan Rilling (1978); Popjak dan Cornforth (1966); Holloway dan Popjak (1968); Bouvier et al, (2000); Burke dan Croteau (2002) menyempurkan laporan tersebut yakni selama reaksi katalis berlangsung, secara geometri mengalami perubahan menjadi cis (4) dan trans (5) (homodimer serta heterodimer) untuk $\mathrm{C}_{5}$.

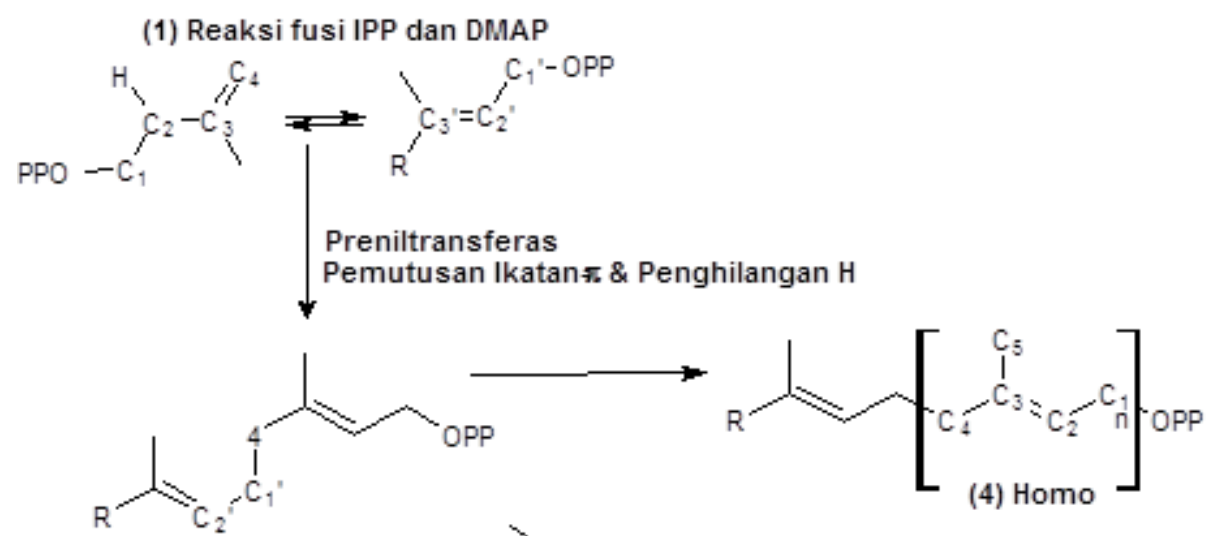

(2) $\mathrm{C}_{5}$ linier (rantai terbuka)

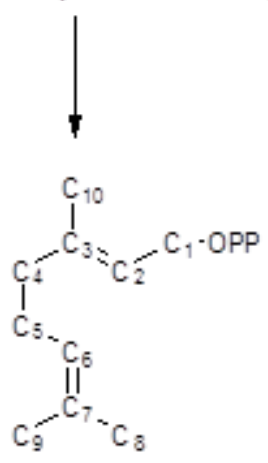

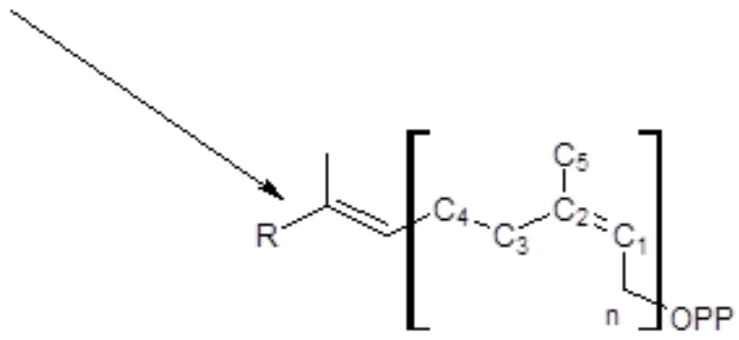

(5) Hetero

(3a) $\mathrm{C}_{10} \mathrm{H}_{20} \mathrm{O}_{7} \mathrm{P}_{2}$

Gambar 1. Fusi antar atom C dan Geometri GPP (sumber modifikasi dari: Poulter, C.D., P.L. Wiggins., A.T. Le. 1981).

Poulter dan Rilling (1976) melaporkan bahwa terdapat energi penggerak sebesar $28 \mathrm{kcal} / \mathrm{mol}$ yang mampu memutar ikatan alilik $\mathrm{C}-\mathrm{C}$, sehingga menyebabkan perubahan geometri GPP rantai terbuka (2) menjadi ikatan benzena GPP-asiklik (3a \& b), dan memiliki kestabilan molekul (struktur ikatan valensi). Thulasiram et al, (2007) dalam percobaannya menemukan pengikatan antar atom yakni siklobutana dan siklopropana.

\section{DARI GPP KE SUB-KELUARGA MONOTERPENA}

Penyebab utama $C_{10}$ sangat banyak karena siklase (berdasarkan sifatnya) mampu memproduksi senyawa turunan dan dikelompokan atas fungsi yakni asiklik atau bisiklik, dan monosiklik (Cane et al., 1991; Croteau et al., 2005; Noma dan Asakawa, 2010). 
CARA GPP MEMBUAT BERAGAM MONOTERPENA

Faktor utama kenapa $\mathrm{C}_{10}$ begitu melimpah, karena terdapat dua molekul yang tidak stabil dengan waktu paruh pendek yakni LPP- transoid (linalil pirofosfat) (5) dan NPPcisoid (neril pirofosfat) (6) adalah hasil reaksi ionisasi serta isomerisasi dari prenyltransferase yang bermula di GPP. Peneliti terdahulu seperti Rojas et al, (1983); Croteau (1987) menyatakan pembentukan GPP, LPP, NPP merupakan postulat, semakin menguatkan ialah hasil percobaan Zhang dan Tiefenbacher (2015) membenarkan mengenai postulat tersebut.

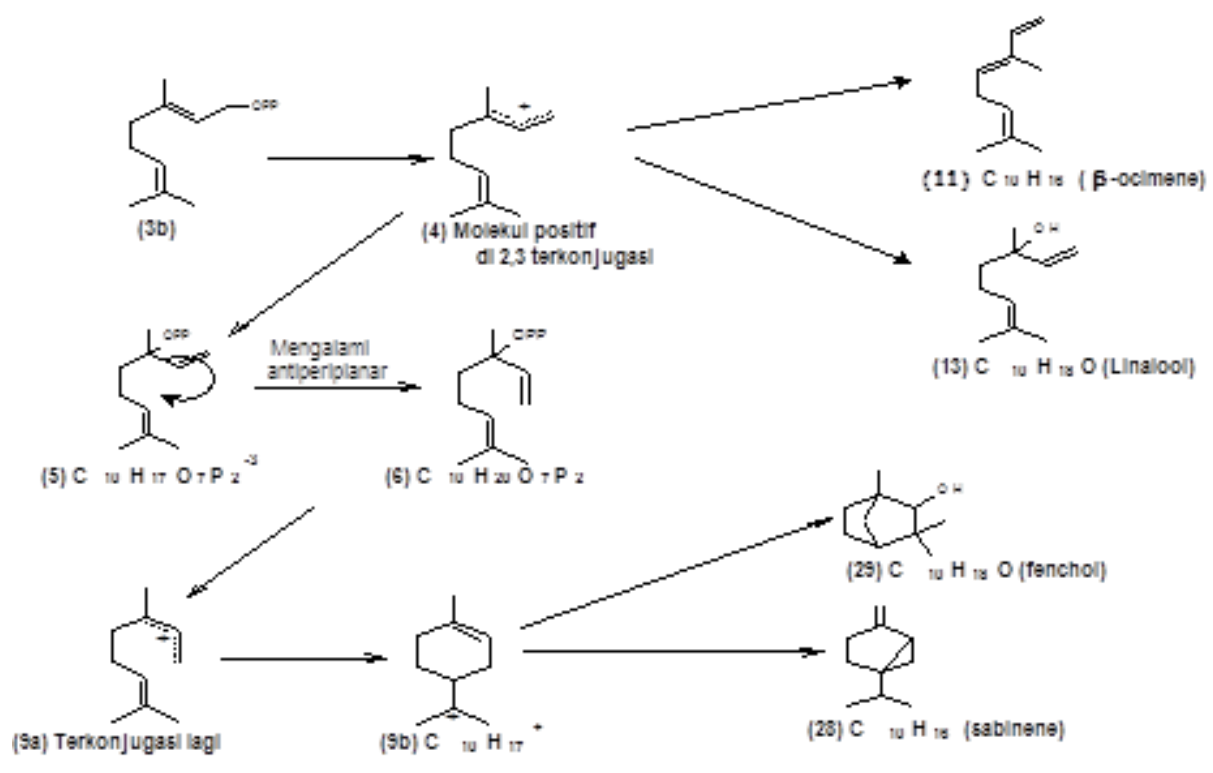

Gambar 2. Postulat dan varietas $C_{10}$ (Sumber modifikasi dari : Croteau. R. 1987).

Pengembangan penelitian biosintesis $\mathrm{C}_{10}$ terus dilakukan sejak, Croteau (1986) sampai sekarang Hyatt et al, (2016) melaporkan bahwa keberhasilan pembuatan substrat analog dan proses kristalisasi 2-fluorin-GPP dan 2-fluorin-LPP sukses memunculkan fluorocineole, fluorobornanes, fluorinated olefins, serta fluorolimonene. Pihak lain yaitu Karp et al, (2007) menyampaikan pada kisaran $6-79 \mu \mathrm{mol} . \mathrm{L}^{-1}$ berfungsi sebagai penghambat dari penggunaan fluoranalog.

\section{MOLEKUL KOMPLEKS MONOTERPENA SIKLASE}

Kajian genetik yang berhasil dirampung oleh Bolhmann et al, (1998) sukses memetakan golongan senyawa terpena yakni Tpsa-Tpsf. Baru-baru ini penelitian MEP dari Jones et al, (2008); Martin dan Bohlmann (2004); Lücker et al, (2002); Yang et al, (2005); Williams et al, (1998); Cane (1999); MacMillan dan Beale (1999); Wise dan Croteau (1999) yakni ke semua hasil cDNA SamonoTPS1, VVTPS, $C L L S, C T G S$ merujuk pada Tpsb, karena memamerkan gen $\mathrm{C}_{10}$ untuk a-terpineol, limonene. Mereka menemukan untaian $323-327$ dan $34-32$ berperan sebagai aktivitas siklase yang kaya aspartat bercorak DDXXDD, serta gen reporter $\mathrm{RRX}_{8} \mathrm{~W}$ berdasarkan sifat gugus bebas menunjukan ujung struktur primer protein ialah aminoterminus. Pemerisaan lanjutan menggunakan metode pemanjangan dan pemotongan klon cDNA memberikan fakta bahwa amino-terminus berfungsi sebagai perpindahan gugus pirofosfat untuk membuat tiga substrat universal yakni $\mathrm{C}_{10}$, seskuiterpena/ $\mathrm{C}_{15}$ (FPP), dan diterpena/ $\mathrm{C}_{20}$ (GGPP) dalam biosintesis semua terpena. Oleh peneliti terdahulu Bolhmann et al, (1998); Lesburg et al, (1997); Tarshis et al, (1994); Williams et al, (1998) sepakat menyatakan corak tersebut membuktikan terdapat protein dengan tugas khusus, untuk semua terpena synthase mengionisasi gugus pirofsfat di substrat awal (3a) karena mengikat unsur $\mathrm{Mn}^{2+} / \mathrm{Mg}^{2+}$. Tapi gen-gen reporter tersebut tidak berlaku untuk semua sekuen protein cDNA $\mathrm{C}_{10}$-synthase.

Rekayasa $\mathrm{C}_{10}$ dari hasil penelitian Lücker et al, (2002); Starks et al, (1997); Rynkiewics et al, (2001); Tarshis et al, (1994); Lesburg et al, (1997) menjelaskan pendayagunaan unsur logam amat substansial, karena sebagai pengaktif siklase. Ini dibuktikan dengan investigasi menyeluruh Citrus limonum, lebih menyukai $\mathrm{Mn}^{2+}$ dari pada $\mathrm{Mg}^{2+}$. Disamping itu efisiensi logam divalent/monovalent menjelaskan bahwa, fraksi $\mathrm{Mn}^{2+}$ berikatan dengan siklase meyebabkan perubahan aktivitas enzim disebabkan perubahan gugus alil karena kesalahan pengklonan gen Citrus limonum. Data-data kristalografi menunjukan struktur tiga dimensi polipeptida dari trichodiene-forming dan ophiobolin-F-forming menampakan kesamaan corak dengan SamonoTPS1 serta terdapat permukaan akti dari GPP untuk mengikat siklase dengan gaya yang relatif lemah untuk membentuk molekul kompleks dari GPP siklase. Penjabaran mengenai molekul $\mathrm{C}_{10}$ dapat disimpulkan bahwa terdapat kesamaan corak dan pemanfaatan senyawa logam. 


\section{PEMBAHASAN}

Uraian molekuler $\mathrm{C}_{10}$ diatas Segel (1968); Chayet et al, (1984); Croteau (1986); Poulter et al, (1981) mencoba menjelakan mengenai siklase dari sisi mekanik, dengan memisalkan LPP, NPP, siklase, dan produk turunannya.

Ketika LPP terikat dengan siklase, maka membentuk suatu senyawa kompleks (LLP-siklase). Kemudian LPPsiklase di ikat oleh NPP sehingga membentuk prekursor kompleks (pada gambar 3 yakni kompleksitas siklase mengikat LPP). Enzim kompleks berlaku sama untuk NPP. Lazimnya secara mekanik guna memperoleh senyawa turunan $\mathrm{C}_{10}$ yakni pertama-tama dengan menurunkan kecepatan reaksi (persamaan 1)

$$
v=k_{p}[\mathrm{EAB}]
$$

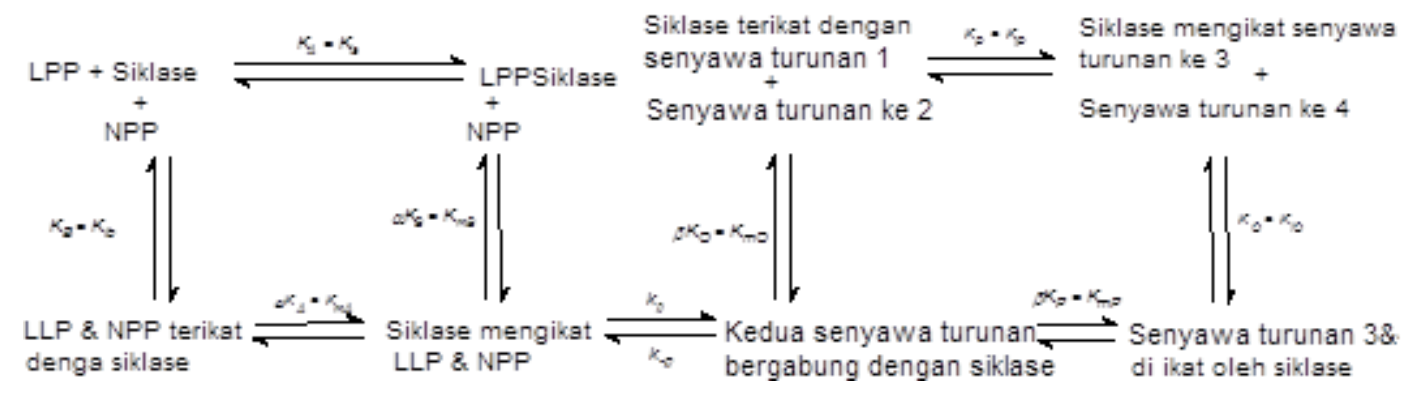

Gambar 3. Alur mekanika siklase guna menghasilkan keragaman C10. Ketrangan lainnya : konstanta disosiasi (KA, KB, $\alpha \mathrm{KA}, \alpha \mathrm{KB})$ dan tingkat kejenuhan LPP serta NPP ( $\alpha \mathrm{KA}(\mathrm{KmA})$ dan $\alpha \mathrm{KB}(\mathrm{KmB})$ ) (Sumber : Segel, I.H. 1968)

Tahapan akhir yakni setelah LPP dan NPP berikatan dengan siklase, baik kecepatan reaksi, konstanta kesetimbangan, dan penurunan aktivitas enzim untuk sistem yang kompleks dapat dicari dengan persamaan (2).

$$
\frac{v}{[\mathrm{E}]_{i}}=\frac{k_{p}[\mathrm{EAB}]}{[\mathrm{E}]+[\mathrm{EA}]+[\mathrm{EB}]+[\mathrm{EAB}]} \ldots \ldots \ldots
$$

Karena setiap jenis siklase memiliki perbedaan sifat, maka terdapat perbedaan kosentrasi dalam sintesis $\mathrm{C}_{10}$. Untuk mencari nilai kosentrasi dapat diselesasikan dengan persamaan (3a).

$\frac{v}{V_{\max }}=\frac{\frac{[\mathrm{A}][\mathrm{B}]}{\alpha K_{A} K_{B}}}{1+\frac{[\mathrm{A}]}{K_{A}}+\frac{[\mathrm{B}]}{K_{B}}+\frac{[\mathrm{A}][\mathrm{B}]}{\alpha K_{A} K_{B}}} \ldots \ldots \ldots$ (3a)

Bentuk lain dari persamaan (3a) yakni persamaan (3b)

$\frac{v}{V_{\max }}=\frac{[\mathrm{A}][\mathrm{B}]}{\alpha K_{\mathrm{A}} K_{B}+\alpha K_{B}[\mathrm{~A}]+\alpha K_{A}[\mathrm{~B}]+[\mathrm{A}][\mathrm{B}]}$

Dengan catatan kecepatan maksimum berbanding lurus dengan konstanta disosiasi produk di kali penghabatan enzim : $V_{\max }=k_{p}[\mathrm{E}]_{i}$

Pemecahan perbedaan kecepatan reaksi dari prekursor kompleks yakni persamaan (3) disusun menjadi persamaan (4).
$\frac{v}{V_{\max }}=\frac{[\mathrm{A}]}{\alpha K_{\mathrm{A}}\left(1+\frac{K_{\mathrm{B}}}{[\mathrm{B}]}\right)+[\mathrm{A}]\left(1+\frac{\alpha K_{\mathrm{B}}}{[\mathrm{B}]}\right)} \ldots \ldots \ldots \ldots$ (4)

Apabila yang dicari adalah nilai dari LPP, maka keceptan NPP perlu diketahui dengan $V_{\max }$ dan $K_{m a_{\text {opp }}}$ adalah tetapan konstanta [NPP]. Asalkan NPP $=\infty$ dan konstanta disosiasi $=0$, maka dapat diselesaikan menggunakan persamaan (5).

$$
\frac{v}{V_{\max }}=\frac{[\mathrm{A}]}{K_{\mathrm{ma}_{\mathrm{opp}}}+[\mathrm{A}]} \ldots \ldots \ldots \ldots
$$

\section{SIMPULAN}

Terobosan terbesar untuk memahami molekul $\mathrm{C}_{10}$ secara mendetail telah berhasil yakni dengan cara mengkonstruksi substrat asli sehingga mengahasilkan substrat analog. Rekayasa substrat analog sukses memproduksi berbagai senyawa $\mathrm{C}_{10}$ secara efisien, dan dengan dukungan kajian mekanika mampu menjelaskan kompleksitas multireaksi siklase. Sehingga para peneliti (yang berkecimpung dalam dunia sintesis $\mathrm{C}_{10}$ ) mengetahui apabila terjadinya kesalahan substrat/siklase dan mutasi pada tingkatan genetik. Walaupun terbosan begitu pesat, tapi di Indonesia belum sampai pada tingkatan molekuler dan genetik $\mathrm{C}_{10}$. 


\section{UCAPAN TERIMAH KASIH}

Terima kasih kepada Kemendikbud atas bantuan dana guna melanjutkan studi magister.

\section{KEPUSTAKAAN}

Banerjee. A., T.D. Sharkey. 2014. Methylerythritol 4phosphate (MEP) Pathway Metabolic Regulation (Review). Nat. Prod. Rep. 31:1043-1055.

Bolhmann. J., G. Meyer-Gauen., R. Croteau. 1998. Plant Terpenoid Synthases: Molecular Biology and Phylogenetic Analysis. PNAS. 95:4126-4133.

Bouvier. F., C. Suire., A. dHarlingue., R.A. Backhaus., B. Camara. 2000. Moleculer Cloning of Geranyl Diphosphate Synthase and Compartmentation of Monoterpene Synthesis in Plant Cell. J. Plant. 24:241-252.

Burke. C., R. Croteau. 2002. Geranyl Diphosphate Synthase From Abies grandis: cDNA Isolation, Functional Expression, and Characterization. Arch. Biochem. Biophys. 405:130-136.

Cane. D. 1979. The Stereochemistry of Allylic Pyrophosphate Metabolism. Tetrahedron. 36:11091159.

Cane. D.E. 1999. Sesquiterpene Biosynthesis: Cyclization Mechanisms. In: Cane. D.E. (Ed.). Comprehensive Natural Products Chemistry: Isoprenoids, Including Carotenoids and Steroids. pp. 155-200. Pergamon Press: Oxford.

Cane. D.E., C. Abell., P.H.M. Harrison., B.R. Hubbard., C.T. Kane., R. Lattman., J.S. Oliver., S.W. Weiner. 1991. Terpenoid Biosynthesis and the Stereochemistry of Enzyme-Catalysed Allylic Addition Elimination Reactions. The Royal Society. 332:123-129.

Chayet. L., M.C. Rojas., O. Cori., C.A. Bunton., D.C. McKenzie. 1984. Complexes of Bivalent Cations with Neryl and Geranyl Pyrophosphate: Their Role in Terpene Biosynthesis. Bioor. Chem. 12:329-338.

Croteau. R. 1986. Evidence for the Ionization Steps in Monoterpene Cyclization Reactions Using 2Fluorogeranyl and 2-Fluorolinalyl Pyrophosphates as Substrates. Arch. Biochem. Biophys. 251:777-782.

Croteau. R. 1987. Biosynthesis and Catabolism of Monoterpenoids. (Review). Am. Chem. Soc. 87:929954.

Croteau. R.B., E.M. Davis., K.L. Ringer., M.R. Wildung. 2005. (-)-Menthol Biosynthesis and Molecular Genetics (Review). Naturwissenschaften. 92:562577.

Devon, T.K., A.I. Scott.1972. Handbook of Naturally Occurring Compounds. Part 2 Terpenes. Academic Press. New York and London.

Dudareva. N., D. Martin., C.M. Kish., N. Kolosova., N. Gorenstein., J. Fäldt., B. Miller., J. Bohlmann. 2003. (E)- $\beta$-Ocimene and Myrcene Synthase Genes of Floral Scent Biosynthesis in Snapdragon: Function and Expression of Three Terpene Synthase Genes of a
New Terpene Synthase Subfamily. Plant Cell. 15:1227-1241.

Dudareva. N., E. Pichersky., J. Gershenzon. 2004. Biochemistry of Plant Volatiles. Plant Physiol. 31:1043-1055.

Hofberger, J.A., A.M. Ramirez., E.V.D. Bergh., X. Zhu., H.J. Bouwmeester., R.C. Schuurink., M.R. Schranz. 2015. Large-Scale Evolutionary Analysis of Genes and Supergene Clusters from Terpenoid Modular Pathways Provides Insights into Metabolic Diversification in Flowering Plants. PLoS. One. 10:137.

Holloway. P.W., G. Popjak 1968. Isopentenyl Pyrophosphate Isomerase from Liver. J. Biochem. 106:835-840.

Hyatt. D.C., B. Youn., Y. Zhao., B. Santhamma., R.M. Coates., R.B. Croteau., CH. Kang. 2016. Structure of Limonene Synthase, a Simple Model for Terpenoid Cyclase Catalysis. PNAS. 104:5360-5365.

Jo Davisson. V., T.R. Neal., C.D. Poulter. 1985. Farnesyl Pyrophosphate Synthetase. A Case for Common Electrophilic Mechanisms for Prenyltransferases and Terpene Cyclases. J. Am. Chem. Soc. 107:5277-5279.

Jones, C.G., C.I. Keeling, E.L. Ghisalberti, E.L. Barbour, J.A. Plummer, J. Bohlmann. 2008. Isolation of cDNA and Fungsional Characterization of Two Multiproduct Terpene Enzymes from Sandalwood, Santalum album L. Arch. Biochem. Biophys. 477:121130.

Karp. F., Y. Zhao., B. Santhamma., B. Assink., R.M. Coates., R.B. Croteau. 2007. Inhibition of Monoterpene Cyclases by Inert Analogues of Geranyl Diphosphate and Linalyl Diphosphate. Arch. Biochem. Biophys. 468:140-146.

Lesburg. C.A., G. Zhai., D.E. Cane., D.W. Christianson. 1997. Crystal Structure of Pentalenene Synthase: Mechanistic Insights on Terpenoid Cyclization Reactions in Biology. Science. 277:1820-1824.

Lücker. J., M.K. El Tamer., W. Schwab., F.W.A. Verstappen., L.H.W. van der Plas., H.J. Bouwmeester., H.A. Verhoeven. 2002. Monoterpene Biosynthesis in Lemon (Citrus limon) cDNA Isolation and Functional Analysis of Four Monoterpene Synthases. Eur. J. Biochem. 269:3160-3171.

MacMillan. J., M.H. Beale. 1999. Diterpene biosynthesis. In: Cane. D.E. (Ed.). Comprehensive Natural Products Chemistry: Isoprenoids Including Carotenoids and Steroids. pp. 217-243. Pergamon Press: Oxford.

Mahmoud, S.S., R.B. Croteau. 2002. Strategies for Transgenic Manipulation of Monoterpene Biosynthesis in Plants (Review). Trends. Plant. Sci. 7:366-373.

Martin. D.M., J. Bohlmann. 2004. Identification of Vitis vinifera (-)- $\alpha$-terpineol Synthase by in Silico Screening of Full-length cDNA ESTs and Functional Characterization of Recombinant Terpene Synthase. Phytochemistry. 65:1223-1229. 
Ministry of Trade of Republic of Indonesia. 2011. Indonesian Essential Oil. The Scant of Natural Life. Handbook of Commodity Profile. Policy Analysis and Development Agency: Ministry of Trade Republic of Indonesia.

Noma. Y., Y. Asakawa. 2010. Biotransformation of Monoterpenoids. in Mander. L., H-W. Liu, (ed) Comprehensive Natural Products II: Chemistry and Biology, (9 ed.). pp. 669-801. Elsevier Ltd: Oxford.

Oyen, L.P.A., N.X. Dung. 1999. Plant Resources of SouthEast Asia. Part 19 Essential-oil plants. Backhuys: Netherlands.

Phillips. M.A., M.R. Wildung., D.C. Williams., D.C. Hyatt., R. Croteau. 2003. cDNA Isolation, Functional Expression, and Characterization of (+)- $\alpha$-pinene Synthase and (-)- $\alpha$-pinene Synthase from Loblolly pine (Pinus taeda): Stereocontrol in Pinene Biosynthesis. Arch. Biochem. Biophys. 411:267-276.

Popjak. G., J.W. Cornforth., 1966. Substrate Stereochemistry in Squalene Biosynthesis. J. Biochem. 101:553-568.

Poulter, C.D., P.L. Wiggins., A.T. Le. 1981. Farnesyl Pyrophosphate Synthetase. A Stepwise Mechanism for the 1'-4 Condensation Reaction. J. Am. Chem. Soc. 103:3926-3927.

Poulter. C. D., H.C. Rilling. 1976. Prenyltransferase: The Mechanism of the Reaction. Biochemistry. 15:10791083.

Poulter. C.D., H.C. Rilling. 1978. The Prenyl Transfer Reaction. Enzymatic and Mechanistic Studies of the $1^{\prime}-4$ Coupling Reaction in the Terpene Biosynthetic Pathway. Am. Chem. Soc. 11:307-313.

Rodrîguez-Concepción. M., A. Boronat. 2002. Elucidation of the Methylerythritol Phosphate Pathway for Isoprenoid Biosynthesis in Bacteria and Plastids. A Metabolic Milestone Achieved through Genomics. Plant. Physiol. 130:1079-1089.

Rohmer. M., M. Seemann., S. Horbach., S. Bringer-Meyer., H. Sahm. 1996. Glyceraldehyde 3-Phosphate and Pyruvate as Precursors of Isoprenic Units in an Alternative Non-mevalonate Pathway for Terpenoid Biosynthesis. J. Am. Chem. Soc. 118:2564-2566.

Rojas. M.C., L. Chayet., G. Portilla., O. Cori. 1983. Substrate and Metal Specificity in the Enzymic Synthesis of Cyclic Monoterpenes from Geranyl and Neryl Pyrophosphate. Arch. Biochem. Biophys. 222:389396.
Rynkiewics. M.J., D.E. Cane., D.W. Christianson. 2001. Structure of Trichodiene Synthase From Fusariumsporotrichioides Provides Mechanistic Inferences on the Terpene Cyclisation Cascade. PNSA. 98:13543-13548.

Segel, I.H. 1968. Biochemical Calculations. How to Solve Mathematical Problems in General Biochemistry Second Edition. John Wiley and Sons. Inc. Canada.

Sharkey. T.D., A.E. Wiberley., A.R. Donohue. 2008. Isoprene Emission from Plants: Why and How (Invited Review). Annals. Botany. 101:5-18.

Starks. C.M., K. Back., J. Chappell., J.P. Noel. 1997. Structural Basis for Cyclic Terpene Biosynthesis by Tobacco 5-Epi-Aristolochene Synthase. Science. 277:1815-1820.

Tarshis. L.C., M. Yan., C.D. Poulter., J.C. Sacchettini. 1994. Crystal structure of Recombinant Farnesyl Diphosphate Synthase at $2.6-\AA$ Resolution. Biochemistry. 33:10871-10877.

Thulasiram. H.V., H.K. Erickson., C.D. Poulter. 2007. Chimeras of Two Isoprenoid Synthases Catalyze All Four Coupling Reactions in Isoprenoid Biosynthesis. Science. 316:73-76.

Williams. D.C., D.J. McGarvey., E.J. Katahira., R. Croteau. 1998. Truncation of Limonene Synthase Preprotein Provides a Fully Active 'Pseudomature' Form of This Monoterpene Cyclase and Reveals the Function of the Amino-Terminal Arginine Pair. Biochemistry. 37:12213-12220.

Wise. M.L., R. Croteau. 1999. Monoterpene biosynthesis. In: Cane. D.E. (Ed.). Comprehensive Natural Products Chemistry: Isoprenoids Including Carotenoids and Steroids. pp. 97-154. Pergamon Press: Oxford.

Yang. T., J. Li., H-X. Wang., Y. Zeng. 2005. A Geraniolsynthase Gene from Cinnamomum tenuipilum. Phytochemistry. 66:285-293.

Zhang. Q., K. Tiefenbacher. 2015. Terpene Cyclization Catalysed Inside a Self-assembled Cavity. Nature. Chem. 7:197-202. 